\title{
INTERPRETIVE SUMMARIES, SEPTEMBER 2013
}

Invited review: Sustainability of the US dairy industry. By von Keyserlingk et al., page 5405. The US dairy industry is under increased scrutiny by social and environmental protection movements, and questions have arisen regarding its long-term sustainability. This review identifies some of the strengths and potential opportunities of the US dairy industry but also suggests that some current production practices are not sustainable. Key factors identified as having the potential to have major effects on the sustainability of the US dairy industry include climate change, rapidly evolving scientific and technological innovation, globalization, failure in integration of societal values (including issues pertaining to animal welfare), and lack of multi-disciplinary research initiatives addressing sustainability.

http://dx.doi.org/10.3168/jds.2012-6354.

Relating sensory and chemical properties of sour cream to consumer acceptance. By Shepard et al., page 5435. The chemical and sensory properties of sour cream were documented to determine drivers of liking. Reduced-fat and fat-free sour creams were characterized by cardboard, acetaldehyde/green, and potato flavors; bitter taste; and astringency; full-fat sour creams lacked these flavors. Lactic acid was the prominent organic acid in all sour creams, followed by acetic and citric acids. High aroma impact volatile compounds in sour creams were 2,3-butanedione, acetic acid, butyric acid, octanal, 2-methyl-3-furanthiol, 1-octene-3-one, and acetaldehyde. Positive drivers of liking for sour cream were milkfat, cooked/milky, and sweet aromatic flavors; opacity; color intensity; and adhesiveness.

http://dx.doi.org/10.3168/jds.2012-6317.

Protein, casein, and micellar salts in milk: Current content and historical perspectives. By Bijl et al., page 5455. Substantial increases have occurred in milk yield and milk protein content over the past decades. However, the effect of this change on other milk constituents, such as the milk salts and their distribution between casein micelles and milk serum, has not been established. Such potential changes are relevant for both processability and the nutritional properties of milk. The objective of this research was to determine current salt composition and protein content of milk and to compare these data to results obtained during the last century in order to establish whether changes have occurred in the salt fraction of milk. http://dx.doi.org/10.3168/jds.2012-6497.

Growth, survival, and peptidolytic activity of Lactobacillus plantarum I91 in a hard-cheese model. By Bergamini et al., page 5465. A strain of
Lactobacillus plantarum (I91) was inoculated and incubated for $21 \mathrm{~d}$ in sterile extracts prepared from young, medium-ripe, and fully ripened hard-cooked cheeses made with 2 different strains of Lactobacillus helveticus as starter. Lactobacillus plantarum I91 grew to similar levels $\left(\sim 10^{8} \mathrm{cfu} / \mathrm{mL}\right)$ in extracts of cheese manufactured with either strain, but afterwards, its viability decreased to an extent dependent on the age of the cheese and the strain of the starter. Lactobacillus plantarum I91 did not contribute significantly to peptidolysis, but differences were found in the catabolism or release of free amino acids between extracts containing different amounts of small nitrogen-containing compounds.

http://dx.doi.org/10.3168/jds.2013-6567.

Role of the microbial population on the flavor of the soft-bodied cheese Torta del Casar. By Martin et al., page 547\%. The volatile fraction and sensory characteristics of raw milk cheese is conditioned by the initial microflora. In this work, counts of lactic acid bacteria (LAB) but also other microbial groups were highly variable among cheese batches studied. The results indicate that the presence of gram-positive catalase positive cocci is necessary to develop the flavor of Torta del Casar and minimize the possible off-flavor derived from excessive concentrations of LAB metabolites such as acetic acid. The application of autochthonous gram-positive catalase positive cocci starter culture in the industry must be considered to obtain a high quality product.

http://dx.doi.org/10.3168/jds.2013-6587.

$\mathrm{pH}$ treatment as an effective tool to select the functional and structural properties of yak milk caseins. By Liu et al., page 5494. Qula is a type of raw casein made from yak milk on the Qinghai-Tibet plateau. To obtain the refined casein, qula must be purified from alkali solutions. Solutions of differing $\mathrm{pH}$ result in different casein yield. However, the functional and structural changes of casein at different $\mathrm{pH}$ are not clear. Different functional properties including solubility, emulsifying activities, and thermal characteristics were evaluated in this study. Our results will help in the production of different caseins suitable for a wide range of industrial applications and will provide useful information on the proper use of caseins in different systems.

http://dx.doi.org/10.3168/jds.2013-6609.

Acceptance of sugar reduction in flavored yogurt. By Chollet et al., page 5501. Several diseases have been associated with a high consumption of sugar; therefore, low intake of this macronutrient is strongly recommended. The dairy industry must reduce the sugar content of processed foods, which is a major 
challenge as products have to be reformulated while maintaining their popularity and appealing character. We organized a consumer test of flavored yogurt to determine an acceptable level of sugar reduction. A second test was conducted to determine the effect of flavoring concentration on the acceptance of sugarreduced yogurt.

http://dx.doi.org/10.3168/jds.2013-6610.

Comparison of functional properties of $34 \%$ and $80 \%$ whey protein and milk serum protein concentrates. By Luck et al., page 5522. Removal of whey proteins before cheese-making provides an alternative route to producing whey proteins ingredients. Serum protein concentrate - whey protein concentrate produced by microfiltration of milk-was compared with traditionally made whey protein concentrate. Both ingredients were manufactured from the same milk lot and under similar conditions so that inherent differences in milk composition were not a variable. Serum protein concentrate, in general, was more soluble and had better foaming and gelation properties than whey protein concentrate. Difference in functional properties could be due to the difference in composition and the extent of protein denaturation or aggregation.

http://dx.doi.org/10.3168/jds.2013-6617.

Genetic variants of bovine $\beta$ - and $\kappa$-casein result in different immunoglobulin E-binding epitopes after in vitro gastrointestinal digestion. By Lisson et al., page 5532. Genetic variants of milk proteins are not considered when discussing the allergenic potential of bovine milk. Our results showed that immunoglobulin (Ig)E-binding epitopes of different $\beta$ - and $\kappa$-casein variants can survive in vitro gastrointestinal digestion. Moreover, differences between the epitopes of $\beta$ - and $\kappa$-casein variants were detected, suggesting an influence of these modifications on the allergenic properties of the proteins. Further studies investigating the allergenic potential of these different peptides by using microarray immunoassays are in progress.

http://dx.doi.org/10.3168/jds.2013-6684.

Casein hydrolysis by Bifidobacterium longum KACC91563 and antioxidant activities of peptides derived therefrom. By Chang et al., page 5544. Free radicals have a negative effect on health, but the defense system of organisms is not sufficient to prevent oxidative damage. The purpose of this study was to investigate potential antioxidant peptide production from peptides released from bovine casein after hydrolysis by Bifidobacterium longum KACC91563.

http://dx.doi.org/10.3168/jds.2013-6687.

Survival analysis as a statistical methodology for analyzing factors that affect milk coagulation time in Holstein-Friesian and Brown Swiss cows. By Cecchinato, page 5556. Milk coagulation properties (MCP; i.e., rennet coagulation time and curd firmness) of dairy cows have been studied because of their association with cheese yield. A critical feature of $\mathrm{MCP}$ data is the presence of noncoagulating (NC) milk records. These records, originating when milk shows no coagulation during the standard 31-min testing time, are usually discarded from statistical analyses. A possible alternative is to consider $\mathrm{NC}$ data as censored records when the rennet coagulation time is outside the measurement range. Here, we show that survival analysis may be used to handle these censored records. Of the potential sources of variation considered in the analysis, our results revealed that herd, days in milk, casein number, and acidity were the most important factors affecting the instantaneous coagulation rate. http://dx.doi.org/10.3168/jds.2013-6720.

Properties of an $\alpha_{\mathrm{S}}$-casein-rich casein fraction: Influence of dialysis on surface properties, miscibility, and micelle formation. By Kessler et al., page 5575. Researchers have been fascinated by the presence of a particular structural entity in milk known as the casein micelle. Even though research on the casein micelle has been conducted for years, questions remain about the properties of the individual constituents of the micelle. In this study, we present results concerning one of the compounds of the casein micelle, $\alpha_{S^{-}}$casein. Our results showed that properties of an $\alpha_{S^{-}}$ casein-rich casein fraction, specifically surface tension, miscibility, and self-assembly, are highly dependent on mineral content. The results are based on the previous development of a new fractionation technique that yielded a food-grade $\alpha_{S^{-}}$casein rich casein fraction. http://dx.doi.org/10.3168/jds.2013-6788.

A low membrane lipid phase transition temperature is associated with a high cryotolerance of Lactobacillus delbrueckii subspecies bulgaricus CFL1. By Gautier et al., page 5591. Lactic acid bacteria, which are widely used as starters in the food industry, are mainly preserved by freezing. However, this step is responsible for cell injury, which will in turn lower the performances and technological properties of starters. The challenge of this work was to gain an understanding of molecular mechanisms involved in the degradation of lactic acid bacteria cells during freezing in order to improve their preservation.

http://dx.doi.org/10.3168/jds.2013-6802.

Microbiological quality and somatic cell count in bulk milk of dromedary camels (Camelus dromedarius): Descriptive statistics, correlations, and factors of variation. By Nagy et al., page 5625. Demand for camel milk is growing in the Middle East and elsewhere. However, the camel dairy industry has only recently been established (in the last decade) 
and it is still in an early stage of development. Hence, information on camel milk quality is scarce. Our study is the first comprehensive report on the long-term monitoring of somatic cell count and microbiological quality in bulk tank milk of dromedary camels. We report basic reference values for somatic cells and bacterial count in bulk camel milk. In addition, we studied interactions between milk quality indicators and defined external factors that influence variation in camel milk quality. http://dx.doi.org/10.3168/jds.2013-6690.

Short communication: Presence of neutral metallopeptidase $(n p r)$ gene and proteolytic activity of Bacillus cereus isolated from dairy products. By Montanhini et al., page 5641. The present study demonstrated the relevance of Bacillus cereus as a spoilage agent in dairy products. The isolates obtained presented proteolytic activity at storage temperature, and possessed the npr gene, related to production of neutral metallopeptidases. The results highlight the importance of controlling $B$. cereus in the dairy industry.

http://dx.doi.org/10.3168/jds.2013-6886.

Periparturient dairy cows do not exhibit hepatic insulin resistance, yet adipose-specific insulin resistance occurs in cows prone to high weight loss. By Zachut et al., page 5656. Insulin signaling in response to the glucose tolerance test (GTT) was examined in liver and adipose tissues of cows $(\mathrm{n}=8)$ at $17 \mathrm{~d}$ prepartum and $4 \mathrm{~d}$ postpartum. Glucose clearance rate was similar; however, basal insulin concentrations, insulin response to GTT, and phosphorylation of hepatic insulin receptor (IR) and protein kinase B (Akt) after GTT were higher prepartum than postpartum, implying that response is correlated with insulin concentrations, without evidence of hepatic insulin resistance. Moreover, adipose tissue phosphorylation of Akt pre- and postpartum was increased in 4 of 8 cows that lost less body weight postpartum. Peripartum adipose-specific insulin resistance occurs in cows prone to high weight loss.

http://dx.doi.org/10.3168/jds.2012-6142.

Hepatic gene expression involved in glucose and lipid metabolism in transition cows: Effects of fat mobilization during early lactation in relation to milk performance and metabolic changes. By Weber et al., page 5670. Hepatic energy metabolism during early lactation is affected by increased energy demands for milk production. As cows differ in fat mobilization around calving, the objective of the study was to investigate the effect of fat mobilization on hepatic gene expression of key enzymes involved in gluconeogenesis and lipid metabolism. Different body fat mobilization affected hepatic mRNA abundance involved in gluconeogenesis, but gene expression involved in lipid metabolism was minimal.

http://dx.doi.org/10.3168/jds.2012-6277.
Prevalence of periparturient diseases and effects on fertility of seasonally calving grazing dairy cows supplemented with concentrates. By Ribeiro et al., page 5682. Prevalence of periparturient diseases and their effects on reproductive performance of seasonally calving grazing dairy cows were characterized. Clinical and subclinical diseases were highly prevalent and associated with delayed resumption of estrous cyclicity, reduced pregnancy per artificial insemination, and increased risk of pregnancy loss. Occurrence of multiple diseases further reduced reproductive efficiency compared with a single disease. Management of grazing cows to optimize fertility should focus on reducing periparturient diseases and lipid mobilization, and improving $\mathrm{Ca}$ homeostasis. Targeting cows to an ideal body condition score at calving should be considered to minimize some of these health problems. http://dx.doi.org/10.3168/jds.2012-6335.

Characterization of a changing relationship between milk production and live weight for dairy goats undergoing extended lactation. By Douhard et al., page 5698. In dairy goat management systems, extending the lactation beyond $300 \mathrm{~d}$ is increasingly considered and it raises the need to characterize extended lactation profiles that can be used for the design of appropriate feeding and culling strategies. This study shows that extended lactation is driven by an increase in resource acquisition, and is then characterized by a delayed transfer of energy from feed to milk. Finally, predicting the suitability of goats for extended lactation requires the consideration of more than just milk production for $300 \mathrm{~d}$ in milk.

http://dx.doi.org/10.3168/jds.2012-6374.

Relation of inflammation and liver function with the plasma cortisol response to adrenocorticotropin in early lactating dairy cows. By Trevisi et al., page 5712. Early lactating cows are often characterized by an inflammation-like status, which causes modifications of the liver function. Severe inflammation reduces the synthesis of negative acute phase proteins for some weeks and metabolic conditions and performance are compromised. Cows with severe inflammation around calving, identified by the liver activity index, showed also the lower response of plasma cortisol (total and bound) after adrenocorticotropin (ACTH) challenge. Therefore, inflammation should be considered for proper interpretation of the plasma cortisol concentration after a stimulation test of the adrenal cortex.

http://dx.doi.org/10.3168/jds.2012-6375.

Implementation of multivariate cumulative sum control charts in mastitis and lameness monitoring. By Miekley et al., page 5723. With growing herd size, the classic detection method of visual obser- 
vations has become more difficult and time consuming. Thus, the need exists to support the farmer's observations by applying improved and automated detection of diseases. This study analyzed the methodology and applicability of multivariate cumulative sum charts, a method from industrial and medical process control, for early mastitis and lameness detection. Requiring at least $70 \%$ block sensitivity, specificities of up to $81 \%$ and error rates of $99 \%$ were reached for mastitis and lameness detection.

http://dx.doi.org/10.3168/jds.2012-6460.

Interaction between dietary content of protein and sodium chloride on milk urea concentration, urinary urea excretion, renal recycling of urea, and urea transfer to the gastrointestinal tract in dairy cows. By Spek et al., page 5734. Milk urea $\mathrm{N}$ (MUN) is positively related to urinary urea $\mathrm{N}$ excretion (UUN) and may serve as a management tool to limit UUN. The MUN is affected by dietary protein and salt. This study investigated the interaction effect between dietary protein and sodium chloride on MUN and showed that there was no such interaction effect. However, the relationship between MUN and UUN was significantly altered by dietary sodium chloride intake. http://dx.doi.org/10.3168/jds.2013-6842.

Comparison of modeled sampling strategies for estimation of dairy herd lameness prevalence and cow-level variables associated with lameness. By Hoffman et al., page 5746. Herd lameness prevalence was estimated within 5 percentage points by locomotion scoring a sample of cows in the middle of a group of cows exiting the milking parlor and by sampling a calculated number of cows distributed evenly across pens. Providing a simple way to estimate lameness prevalence in a dairy herd could initiate discussions between producers and advisors on ways to reduce this condition among cows.

http://dx.doi.org/10.3168/jds.2013-6891.

Survey of animal-borne pathogens in the farm environment of 13 dairy operations. By Toth et al., page 5756. The prevalence of pathogens in the farm environment was measured on 13 dairy operations. Cow and calf feces, bedding material, stored manure, milk filters, soil, and stream water were analyzed for Salmonella, Escherichia coli O157:H7, Campylobacter, Mycobacterium, and the parasite Cryptosporidium. Escherichia coli O157:H7 and Mycobacterium were detected most frequently, in 19 and $20 \%$ of samples, respectively. Salmonella, Campylobacter, and Cryptosporidium were present at lower frequencies. Pathogens were found in $73 \%$ of stored manure and $50 \%$ of the fecal samples. The widespread occurrence of pathogens on dairy farms constitutes a potential threat to public health if the organisms move into the environment. http://dx.doi.org/10.3168/jds.2012-6499.
Short communication: Change in dose delivery of prostaglandin $\mathbf{F}_{2 \alpha}$ in a 5-day timed artificial insemination program in lactating dairy cows. By Stevenson et al., page 5769. Two experiments determined if a larger dose of prostaglandin $\mathrm{F}_{2 \alpha}(\mathrm{PG})$ on d 6 would induce luteolysis in a traditional 5 -d timed artificial insemination (AI) program. Lactating dairy cows were enrolled before AI for first or repeat services. Luteal tissue area and blood progesterone decreased in response to $\mathrm{PG}$ delivered on $\mathrm{d} 6$ as well as that delivered on $\mathrm{d} 5$ and 6 . In a second experiment, progesterone confirmed luteolysis in both treatments. On the basis of luteal tissue regression and decreased progesterone, it was concluded that $50 \mathrm{mg}$ of PG on d 6 was equal to a standard 25-mg dose administered on d 5 and 6 .

http://dx.doi.org/10.3168/jds.2013-6845.

Technical note: Evaluation of odor from vaginal discharge of cows in the first 10 days after calving by olfactory cognition and an electronic device. By Sannmann et al., page 5773. The evaluation of odor from vaginal discharge of cows in the first $10 \mathrm{~d}$ postpartum is an important criterion for the diagnosis of acute postpartum metritis. This study demonstrated a considerable subjectivity of the human nose concerning the classification into healthy and metritic cows based on the olfactory assessment of vaginal discharge. The repeatability of an electronic nose device was higher. Sensitivity and specificity of olfactory evaluation was 75.0 and $60.1 \%$ compared with 92.0 and $100 \%$ for the electronic nose device.

http://dx.doi.org/10.3168/jds.2013-6813.

Extended negative dietary cation-anion difference feeding does not negatively affect postpartum performance of multiparous dairy cows. By Weich et al., page 5780. The effects of feeding negative dietary cation-anion difference (DCAD) for 21 or 42 d on transition cow calcium $(\mathrm{Ca})$ homeostasis, energy status, and postpartum performance were investigated. Cows were fed a negative DCAD $(-16 \mathrm{mEq} / 100 \mathrm{~g}$ of $\mathrm{DM})$ for 21 or $42 \mathrm{~d}$ before calving or a positive DCAD $(+12 \mathrm{mEq} / 100 \mathrm{~g}$ of DM) for $42 \mathrm{~d}$ before calving. Cows fed the negative DCAD tended to have greater postpartum total blood Ca compared with cows fed the positive DCAD. Cows fed negative DCAD for $42 \mathrm{~d}$ prepartum tended to have greater postpartum total blood Ca than cows fed negative DCAD for $21 \mathrm{~d}$ prepartum. Feeding a negative DCAD for $21 \mathrm{~d}$ prepartum resulted in higher milk yield during the first $56 \mathrm{~d}$ of lactation compared with cows fed a positive DCAD prepartum. Milk yield for cows fed negative DCAD prepartum diets for $42 \mathrm{~d}$ was similar to the $21 \mathrm{~d}$ treatment.

http://dx.doi.org/10.3168/jds.2012-6479.

Effect of short-term versus long-term grassland management and seasonal variation in organic 
and conventional dairy farming on composition of bulk tank milk. By Adler et al., page 5793. Bulktank milk from 28 dairy farms was analyzed for fatty acid composition, fat-soluble vitamins, selenium, and sensory quality in a 2-yr study to assess effects of grassland management (short vs. long time since grassland establishment), production system (organic vs. conventional), and season. Grassland management had minor effects on milk composition, whereas effects of production system and season were pronounced. Organically produced milk had higher proportions of some fatty acids and concentration of selenium, but also higher proportions of saturated fatty acids. Milk produced on pasture had higher concentrations of beneficial fatty acids than milk produced on preserved forage. http://dx.doi.org/10.3168/jds.2012-5765.

Calving body condition score affects indicators of health in grazing dairy cows. By Roche et al., page 5811. Pasture-based multiparous cows were managed to generate groups with three different calving body condition scores (BCS) at calving (BCS 3.5, 4.5, and 5.5, in the 10-point scale system). Milk and fat yields, BCS loss, and the concentration of metabolites associated with negative energy balance postcalving were positively associated with calving BCS. Thinner cows were more prone to reproductive compromise, whereas fatter cows had an increased risk of metabolic diseases. Results are consistent with recommendations that optimum calving BCS for grazed multiparous dairy cows is 4.5 to 5.0 ( 3.0 on a 5 -point scale), but do not support the use of BCS as a predictor of animal welfare.

http://dx.doi.org/10.3168/jds.2013-6600.

Intake of specific fatty acids and fat alters growth, health, and titers following vaccination in dairy calves. By Esselburn et al., page 5826. Including a specific amount of butyric, medium-chain, and linolenic acids in milk replacers that were low in these fatty acids (and based on animal fat) improved body weight gain, hip width growth, feed efficiency, and titers following vaccination while reducing days with abnormal fecal scores and skin tail temperature in dairy calves less than 2 mo of age. Similarly, feeding dried milk, high in these fatty acids, of similar crude protein concentration (27\%) but higher fat $(33 \%$ vs. $17 \%$ ) improved body weight gain, hip width growth, and feed efficiency, and increased skin tail temperature but not titers following vaccination.

http://dx.doi.org/10.3168/jds.2013-6608.

Passage kinetics of ${ }^{13} \mathrm{C}$-labeled corn silage components through the gastrointestinal tract of dairy cows. By Warner et al., page 5844. Fractional passage of feed determines the time that feed is retained in the digestive tract of an animal and is essential to predict absorption and excretion of nutrients and waste products. Most modern feed evaluation systems assume fixed fractional passage rates, based on external markers, for different feed types and components. This study shows that the stable isotope ${ }^{13} \mathrm{C}$ can be used to trace feed components of corn silage passing through the digestive tract of dairy cows. Rates determined using ${ }^{13} \mathrm{C}$ differed among carbohydrate fractions and from rates estimated with the external marker Cr-NDF (chromium neutral detergent fiber).

http://dx.doi.org/10.3168/jds.2013-6694.

Prepartum nutritional strategy affects reproductive performance in dairy cows. By Cardoso et al., page 5859. Cows that received controlled energy diets during the last 4 wk prepartum became pregnant sooner than cows that received high energy diets. Effects may be explained by increased net energy for lactation intake in the first 4 wk postpartum and lower incidence of diseases for controlled energy. In addition, less BCS loss in the first 6 wk and slightly higher glucose concentrations at wk 3 may have contributed to improved reproductive performance.

http://dx.doi.org/10.3168/jds.2013-6759.

Analysis of rumen microbial populations in lactating dairy cattle fed diets varying in carbohydrate profiles and Saccharomyces cerevisiae fermentation product. By Mullins et al., page 5872. More than 140 unique rumen digesta samples were used for analysis of 12 well-described rumen microbe populations. In agreement with previous reports, culturable microbes represented a small proportion of total bacteria in the rumen. Aside from an interaction of Saccharomyces cerevisiae fermentation product and quadratic effect of preliminary dry matter intake $(P=0.06)$ with the population of Eubacterium ruminantium, no significant effects of dietary treatments on microbial populations were detected. Several species were significantly more abundant in either the liquid or solid fraction of rumen digesta; on average, $92 \%$ of total bacterial DNA was found in the solid fraction. Additionally, the abundance of several populations was found to change by 2 - to 3 -fold in the course of a 24 -h period.

http://dx.doi.org/10.3168/jds.2013-6775.

Effect of replacing grass silage with red clover silage on ruminal lipid metabolism in lactating cows fed diets containing a 60:40 forage-toconcentrate ratio. By Halmemies-Beauchet-Filleau et al., page 5882. The effect of incremental replacement of grass silage with red clover silage on ruminal lipid metabolism was examined in lactating cows. Substitution of grass silage with red clover silage progressively lowered lipolysis of dietary esterified lipids and apparent biohydrogenation of 18-carbon unsaturates in the rumen, and increased the flow of 18:2n- 6 and 18:3n-3 at 
the omasum. Forage species alters the transformation of dietary lipid in the rumen and modifies the flow of lipid fractions and specific fatty acids at the omasum. http://dx.doi.org/10.3168/jds.2013-6872.

Short communication: Interrelationship between butyrate and glucose supply on butyrate and glucose oxidation by ruminal epithelial preparations. By Wiese et al., page 5914. This study sought to determine whether dietary butyrate supplementation altered glucose and butyrate oxidation by the ruminal epithelium and whether acute changes in substrate availability modulated substrate oxidation. The results of this study demonstrated that dietary butyrate supplementation can decrease glucose oxidation by the ruminal epithelium and thus provided evidence that dietary butyrate supplementation can be used to spare glucose oxidation by the reticulo-rumen epithelium. However, the relative supply of glucose and butyrate also affects substrate oxidation.

http://dx.doi.org/10.3168/jds.2013-6677.

Short communication: Fractional milking distribution of immunoglobulin G and other constituents in colostrum. By Vetter et al., page 5919. Newborn dairy calves do not receive immune protection in utero and many receive inadequate immunoglobulin $\mathrm{G}$ ( $\operatorname{Ig} G$ ) from maternal colostrum. This is partly because some cows produce colostrum with a low concentration of IgG and the calf has limited capacity for the consumption of volume and a period of only $1 \mathrm{~d}$ to absorb the IgG to gain protection from intestinal disease. Previous research has indicated that colostrum concentration is not different during the course of milking, but the reports are not clear because of large variation in colostrum concentration and low animal numbers. If a difference in first-milked colostrum concentration occurs during milking, we hypothesized that it would be possible to feed the newborn the higher concentration fraction and gain greater IgG absorption, thus providing better disease protection. Our analysis indicated no difference in IgG concentrations between equally divided fractions of first-milked colostrum. http://dx.doi.org/10.3168/jds.2013-6745.

Multiple-trait random regression models for the estimation of genetic parameters for milk, fat, and protein yield in buffaloes. By Borquis et al., page 5923. Buffalo milk is rich in solid components and this property is valuable to the milk industry. The application of the multiple-trait random regression methodology allowed us to obtain information for the entire lactation curve and evaluate the relationship among the traits of economic interest in dairy buffalo production systems. Thus, the objective of this study was to estimate genetic parameters for buffalo fat, protein, and milk yields, using Bayesian inference. http://dx.doi.org/10.3168/jds.2012-6023.
Genetic components of milk Fourier-transform infrared spectra used to predict breeding values for milk composition and quality traits in dairy goats. By Dagnachew et al., page 5933. Milk component phenotypes are typically predicted using Fouriertransform infrared (FTIR) spectra and, together with pedigree information, they are used in best linear unbiased predictor (BLUP) for estimation of individual estimated breeding values (EBV) - the indirect approach (IP). An alternative method is proposed, the direct approach (DP), where genetic evaluation of individuals based on several hundred milk FTIR spectral variables. For the DP approach, spectral dimension was reduced using multivariate technique. The DP approach yielded more accurate EBV for fat, lactose, and protein percentages compared with the IP approach. The potential and application of the DP method could be extended to any spectroscopy techniques implemented in breeding schemes for different species.

http://dx.doi.org/10.3168/jds.2012-6068.

Estimation of genetic parameters for novel functional traits in Brown Swiss cattle. By Kramer et al., page 5954. In this study, genetic parameters and accuracies of breeding values were estimated for a set of functional, behavioral, and conformation traits in Brown Swiss cattle. The results showed that behavior traits in dairy cattle can have a relatively high heritability if measurement is done assiduously. Reasonably accurate breeding values can be estimated with a relatively small number of phenotyped animals. Moderate heritability was found for the novel conformation trait position of labia, which is functionally correlated with urovagina; consideration of this trait could help to reduce impaired fertility.

http://dx.doi.org/10.3168/jds.2012-6236.

Estimation of genetic parameters for individual udder quarter milk content traits in Brown Swiss cattle. By Kramer et al., page 5965. We analyzed phenotypes recorded separately for the 4 udder quarters of 1,799 Brown Swiss cows. We found that the contents of fat, protein, and lactose differed significantly between front and rear udder quarters. We also observed systematic differences in the heritability and reduced additive genetic correlations between front and rear udder quarters for most of the milk content traits. These results indicate that milk contents of different udder quarters can be considered as genetically different traits. Some of the results reflect the different physiological basis of the traits.

http://dx.doi.org/10.3168/jds.2013-7188.

Genetic variance in micro-environmental sensitivity for milk and milk quality in Walloon Holstein cattle. By Vandenplas et al., page 597r. In the current dairy industry, animals that are robust to 
environmental changes are desirable. Genetic differences in micro-environmental sensitivity can be studied through heterogeneity of residual variance between animals. The objective of this research was to study genetic heterogeneity of residual variance by estimation of variance components in residual variance for milk yield, somatic cell score, and contents in milk $(\mathrm{g} / \mathrm{dL})$ of saturated fatty acids, unsaturated fatty acids, and C18:1 cis-9 for first-parity Holstein cows in the Walloon Region of Belgium.

http://dx.doi.org/10.3168/jds.2012-6521.

Genetic analysis of Fourier-transform infrared spectra of bovine milk with emphasis on individual wavelengths related to specific chemical bonds. By Bittante and Cecchinato, page 5991. The absorbance data from Fourier-transform infrared (FTIR) spectra are currently used to predict the fat, protein, casein, and lactose contents of milk and propose new milk-related phenotypes. This study shows that the absorbance values of most FTIR spectrum waves are heritable, and thus may be used directly for breeding purposes.

http://dx.doi.org/10.3168/jds.2013-6583.

Association of polymorphisms in solute carrier family 27, isoform A6 (SLC27A6) and fatty acid-binding protein-3 and fatty acid-binding protein-4 (FABP3 and FABP4) with fatty acid composition of bovine milk. By Nafikov et al., page 600\%. Fatty acid composition of bovine milk is an important determinant of milk technological properties, such as for production of more spreadable butter and milk nutritional value with respect to potential adverse effects of certain saturated fatty acids (FA) on human health. The objective of our study was to discover single nucleotide polymorphisms (SNP) in genes involved in FA transport during milk lipid biosynthesis for the selection of animals producing milk with lower concentration of saturated FA and higher concentrations of unsaturated FA. The results indicated the existence of SNP that would allow dairy producers to obtain milk with desirable FA composition.

http://dx.doi.org/10.3168/jds.2013-6703.

Investigating the effect of two methane mitigating diets on the rumen microbiome using massively parallel sequencing. By Ross et al., page 6030. This work identified links between the microbial community of the dairy cow rumen and enteric methane production. Changes in rumen microbial population were assessed using untargeted (shotgun) massively parallel sequencing. The collection of microbes that inhabits the rumen of cattle was shown to vary significantly and consistently when enteric methane production was decreased via 2 dietary additives. The markers (genome fragments) identified for low methane production were validated in an independent cohort of cattle that showed natural variation in methane production. Possible rumen biomarkers for low-methane emitting-cattle have been identified, which warrant further investigation.

http://dx.doi.org/10.3168/jds.2013-6766.

Assets of imputation to ultra-high density for productive and functional traits. By JiménezMontero et al., page 604\%. Imputation of genotypes from lower to higher density panels is an important strategy for optimizing genomic selection programs. We performed genotype imputation from $3 \mathrm{~K}(\sim 3,000)$ and $6 \mathrm{~K}$ $(\sim 6,000)$ assays to $50 \mathrm{~K}(\sim 50,000)$ and $800 \mathrm{~K}(\sim 800,000)$ densities with allele error rates $<2 \%$. In general, some improvement in the predictive accuracy was obtained after imputation to ultra-high density. Genetic and genomic evaluation units should consider using different methods regarding the trait evaluated, and imputation to ultra-high density might be interesting to increase the predictive ability of some traits, especially those of low heritability or regulated by major genes. http://dx.doi.org/10.3168/jds.2013-6793.

Identification of quantitative trait loci underlying milk traits in Spanish dairy sheep using linkage plus combined linkage and linkage disequilibrium approaches. By Garcia-Gámez et al., page 6059. The development of tools derived from genome sequencing projects in ruminants allows start projects to elucidate the genetic architecture of milk traits in domestic species. In this study, we used the ovine medium-density single nucleotide polymorphism (SNP) chip $(50 \mathrm{~K}, \sim 50,000)$ to identify quantitative trait loci influencing milk production traits in Spanish sheep. The availability of these genomic tools allows the use of more powerful analytical procedures and, therefore, the more accurate identification of genomic regions harboring loci underlying milk traits.

http://dx.doi.org/10.3168/jds.2013-6824.

Genetic parameters for claw disorders and the effect of preselecting cows for trimming. By van der Spek et al., page 60\%0. Claw disorders are important traits from an economical and a welfare point of view. Our objectives were to estimate heritabilities and genetic correlations for claw disorders and to investigate the effect of selecting cows for trimming. Claw disorders are heritable and that selecting cows for trimming does not influence heritabilities, but selecting herds where a certain percentage of cows were trimmed does. Furthermore, the need for trimming is a heritable trait and interesting to include in genetic evaluations.

http://dx.doi.org/10.3168/jds.2013-6833.

Short communication: Analysis of association between prion protein $(P R N P)$ locus and milk 
traits in Latxa dairy sheep. By Vitezica et al., page 6079. Scrapie is a transmissible spongiform encephalopathy that affects sheep. Resistance or susceptibility of sheep to scrapie is mainly controlled by the prion protein $(P R N P)$ gene. Selection programs for scrapie resistance have been implemented in Europe. Including the $P R N P$ genotype in breeding objectives might cause undesirable changes in other economically important production traits, such as milk yield. In this study, the potential association between $P R N P$ genotypes and ewe milk traits was investigated. The results indicate that it is unlikely that selection for scrapie resistance will have an effect on the milk traits studied in the Latxa breed. http://dx.doi.org/10.3168/jds.2013-6570.

Carbon footprint of Canadian dairy products: Calculations and issues. By Vergé et al., page 6091. An integrated on-farm/off-farm model was developed and used to estimate the carbon footprint (CF) of 11 Canadian dairy products, from the cradle to the dairy manufacturing plant's gate. On-farm emissions contributed about $90 \%$ of greehouse gas (GHG) emissions and the remaining $10 \%$ came from transportation and the processing plants. The $\mathrm{CF}$ per kilogram of product ranged from 1 to $10 \mathrm{~kg}$ of $\mathrm{CO}_{2}$ equivalents $\left(\mathrm{CO}_{2} \mathrm{e}\right)$; most of the values were close to $2 \mathrm{~kg}$ of $\mathrm{CO}_{2} \mathrm{e}$. Emissions per kilogram of protein ranged from 12 to $730 \mathrm{~kg}$ of $\mathrm{CO}_{2} \mathrm{e}$. This study demonstrated that the use of a common food component is not always suitable as a comparison unit. http://dx.doi.org/10.3168/jds.2013-6563.
Views on contentious practices in dairy farming: The case of early cow-calf separation. By Ventura et al., page 6105. The dairy industry requires mechanisms that allow for sharing views on contentious issues. The current study used an online forum to elicit perspectives on whether dairy calves should be separated from the cow soon after birth. We found little evidence of participant consensus, but opponents and supporters often referenced similar issues (e.g., cow and calf stress and calf health) in their reasoning, providing a basis for identifying practices that better meet both producer and consumer expectations.

http://dx.doi.org/10.3168/jds.2012-6040.

The economic value of organic dairy farms in Vermont and Minnesota. By O'Hara and Parsons, page $611 \%$. The organic dairy sector has enabled some pasture-based dairies to maintain economic viability that otherwise would have gone out of business. We quantified the economic impacts of these farms in Vermont and Minnesota. Financial data for both conventional and organic dairy farms were collected and assembled to develop dairy farm production functions for use in "input-output" models to calculate economic impacts. The study found that organic dairy farms had relatively greater regional economic impacts than did conventional dairy farms in both states.

http://dx.doi.org/10.3168/jds.2013-6662. 